\title{
Executive Summary of the Fifth Edition of the Renal Association Clinical Practice Guidelines (2009-2012)
}

\author{
Dr Robert A Mactier ${ }^{\mathrm{a}}$ and Dr Charles RV Tomson ${ }^{\mathrm{b}}$ \\ ${ }^{a}$ Consultant Nephrologist, NHS Greater Glasgow \& Clyde and Chair, Renal Association Clinical Practice \\ Guidelines Committee \\ ${ }^{\mathrm{b}}$ Consultant Nephrologist, North Bristol NHS Trust and President, Renal Association
}

\section{Key Words}

Renal Association - clinical practice guidelines - GRADE - peer review $\cdot$ NHS Evidence $\cdot$ audit $\cdot$ quality improvement

\section{Introduction}

The Renal Association (RA) Clinical Practice Committee produces guidelines for the entire renal community in the UK. The Clinical Practice Guidelines Committee is one of three committees of the Clinical Affairs Board of the RA, the others being the Clinical Services Committee and Renal Registry Committee. The guidance within the RA Clinical Practice Guidelines supports the drive to improve renal services in the UK as described in The National Service Framework for Renal Services Part 1: Dialysis and Transplantation [1]; The National Service Framework for Renal Services Part 2: CKD, acute renal failure and end of life care [2]; Designed to Tackle Renal Disease in Wales [3] and

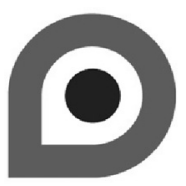

NHS Evidence Accreditation Mark publications by NHS Quality Improvement Scotland (QIS) [4].

The current (fifth) edition of the clinical practice guidelines has been expanded to 14 separate modules covering the main subject areas in the management of patients with acute kidney injury and chronic kidney disease, including specialist guidance on all of the major topics in dialysis and transplantation. The modular format facilitates wide peer review, more rapid publication than a single document and allows interim updating of individual guideline modules as and when required. The recommendations on the management of patients with renal disease are supported by an evidence based rationale followed by a list of the references which were cited in the rationale. Audit measures are included with the recommendations whenever this is appropriate. Thus the guidance provides an up-to-date template for current best practice in the management of renal disease within the UK healthcare system, serves to define the dataset collected by the UK Renal Registry, and includes clinical performance measures which may be used for local, regional and national audit.

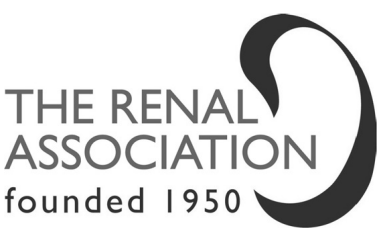

\section{KARGER}

Fax +4161306 1234 E-Mail karger@karger.ch www.karger.com
(C) $2011 \mathrm{~S}$. Karger AG, Basel

$1160-2110 / 11 / 1185-0005 \$ 38.00 / 0$ 
The RA was founded in 1950 and the last modules of the fifth edition were completed recently. This e-publication supplement issue of Nephron Clinical Practice promotes dissemination of the guidelines and serves as an archive of the guidelines shortly after the 60th anniversary of the RA.

\section{History of the Renal Association guidelines}

The RA guidelines were published as 'clinical standards' for the first three editions (1995-2007) before converting to a standard modular format for the 4th edition in 2007-2009 and the current 5th edition which commenced in 2009. The approach taken to the evidence base has changed radically since 1995 . The 1st and 2nd editions gave 'recommended standards' when the evidence was 'strong' and 'recommendations' when the evidence was weaker. The 3rd edition adopted the term 'standard' when either the evidence was strong or when making key 'good practice' statements and added that it should be possible to audit a 'standard'. A threetier grading $(\mathrm{A}, \mathrm{B}, \mathrm{C})$ for quality of evidence was also used, in which level A evidence comprised meta-analyses (level 1a) or at least one randomised controlled trial (level 1b); B comprised well-conducted clinical studies with extensive but largely descriptive evidence (level IIa, IIb, IIc, III); and C comprised expert committees or reports (level IV). For the 4th edition of the RA guidelines the supporting evidence for the clinical practice recommendations was qualified as 'Evidence' when based on randomised controlled trials or systematic reviews or 'Opinion' for all other lower levels of evidence. An archive of the first four editions of the RA guidance is available on the old guidelines page of the RA website [5].

\section{Guideline development process}

The process of development of the guidelines has undergone serial improvements in recent years. The Clinical Practice Guidelines Committee introduced two cycles of peer review by the membership of the RA and invited stakeholders in May 2008 and the modified GRADE system for grading of recommendations has been used in all guideline modules since January 2009.

The modified GRADE system provides an informative, transparent summary for clinicians, patients and policy makers by combining an explicit evaluation of the strength of the recommendation with a judgement of the quality of the evidence for each recommendation $[6,7]$. Each recommendation is worded using the format of the modified GRADE system i.e. either 'we recommend' (strong recommendation $=1$ ) or 'we suggest' (weak recommendation $=2$ ). The use of the active voice 'we' indicates that the RA clinical practice guideline co-authors, on behalf of the Clinical Affairs Board, take responsibility for the guidance provided. The level of evidence is graded A-D to give a clear indication of the strength of the supporting evidence upon which the recommendation is based. Thus the grading of recommendations ranges from $1 \mathrm{~A}$ to $2 \mathrm{D}$. Using the GRADE system, 'good practice' statements are ungraded. The widespread implementation of clinical practice guidelines has been reported to have potentially negative as well as positive implications and outcomes for clinical care [8].

The co-authors of each module are selected by the Clinical Affairs Board and invited by the Chair of the guidelines committee to contribute to the development of each module based on their known interest and expertise in the subspecialty area and because they are free of overt conflicts of interest from being closely involved with major commercial providers of renal replacement therapy technology, disposables and drugs. To balance the need to maintain continuity and to reduce duplication and repetition with the need to ensure that the guidelines are renewed in the light of new evidence, one author of the 4th edition guideline (where applicable) is retained, and one is replaced for each revision.

The co-authors of each module draft and agree the recommendations within each module. The key evidence considered in determining the recommendations is described in the rationale after each recommendation or group of recommendations and this evidence base is referenced after each rationale section. The rationale describes the strengths and weakness of the evidence provided by these publications and provides a chain of logic and reasoning for the issued guidance. The recommendations and their grading are subject to two cycles of feedback via an email invitation to all members of the RA via the monthly eNews when the first and final drafts are published on the RA website. Over $90 \%$ of consultant nephrologists in the UK are members of the RA. In addition the co-authors of the guideline modules request feedback from invited stakeholders, relevant specialist societies and patient representatives. The recommendations (and grading) may then be changed by the co-authors for the final draft and final versions. The final version, and the evidence that consultation has 
taken place and been taken into account, is scrutinised carefully by the Clinical Affairs Board and, once approved, the guideline module is locked and published on the website as the final version [9].

All of the current guidelines have the date of completion of the current guideline and the date for updating the guidance clearly displayed on the RA website main guidelines page. If important new information from high quality studies becomes available (e.g. a randomised controlled trial is published in between planned updates) the electronic website modular format permits recommendations to be changed if deemed appropriate and endorsed by the Clinical Affairs Board.

Each guideline contains a number of audit measures to assist with implementation of the guidance, promote an improvement in the quality of care and allow comparative audit. The audit measures should be measurable, achievable and serve as evidence based criteria for continuing quality improvement. A summary of all of the audit measures in each module is included before the rationale section of all of the recommendations.

\section{Accreditation by NHS Evidence}

The process used in the preparation of the RA clinical practice guidelines is summarised in the main guidelines page on the RA website and described in detail in the guideline development policy manual [9].

This guideline development process was used in the preparation of all of the guideline modules in the fifth edition and was submitted for accreditation by NHS Evidence in February 2010. The RA guideline process was assessed as having fulfilled all 25 criteria within the 6 different domains for accreditation and accreditation was approved by NHS Evidence at its meeting in October 2010 [10]. Accreditation is valid for 3 years from November 2010 and is retrospectively applicable to all guidance in the fifth edition produced since January 2009 using the processes described in the RA Clinical Practice Guidelines Development Policy Manual published in the next section of this supplement and on the RA website [9].

\section{Clarity of presentation}

The modules have been designed to make the guidance user-friendly. The recommendations are written in plain
English with an emphasis on using standard, consistent and up-to-date terminology to avoid ambiguity (e.g. 'acute kidney injury' instead of 'acute renal failure', 'established renal failure' instead of 'end-stage renal failure').

The standard format used for all modules of the fifth edition of the RA guidelines is as follows:

\section{Title page}

Email and mail addresses of all co-authors are listed on this page along with the full title and date of the guideline.

\section{Contents page}

The summary of clinical practice guidelines on this page describes all of the subject headings used in the guideline and the recommendations within each subject heading are numbered consecutively.

\section{Introduction}

This section includes a brief background, a description of the method and date of the literature search, description of the use of the modified GRADE system and links (if any) with other guidelines.

4. Summary of all clinical practice recommendations

Each guideline module has a summary of the clinical practice recommendations after the contents and introduction. This section of the module can be readily downloaded from the RA website as a concise summary of the recommendations without needing to read, download or print the entire guideline document. All recommendations should be graded using the modified GRADE system unless adapted from other guidelines.

\section{Summary of all audit measures}

All audit measures should be clinical performance indicators which are derived from the guideline recommendations and need to be measurable, objective, unambiguous and achievable.

\section{Rationale of the clinical practice recommendations}

Each recommendation or group of recommendations should be followed by the evidence, chain of logic and references cited in the rationale to support the guidance.

\section{Acknowledgements}

This section should include an acknowledgement of contributions from other members of the RA, stakeholders and patients. Endorsement by other specialist societies (if any) should be included in this section. The co-authors should declare all potential conflicts of interest. 


\section{Applicability of the guidelines}

The prevalence of CKD and the need for renal replacement therapy is higher in ethnic subgroups of the population e.g. Asian, Afro-Caribbean and the guidance applies equally to all adult patient groups regardless of race, disability, gender or age. Separate guidelines on the management of renal disease in children is prepared in the UK by the British Association of Paediatric Nephrology (BAPN), which was affiliated to the RA in 2010.

The close link with the Renal Registry promotes implementation of the guideline recommendations and the achievement of performance indicators. The main objective is to improve clinical practice in renal services nationwide; although it is impossible to claim a causal relationship, the UK Renal Registry has reported progressive improvements in kidney patient outcomes in recent years [11].

\section{Dissemination and availability of the guidelines}

All of the membership of the RA is sent an invitation via the monthly eNews for feedback on each draft version of the guidelines and notification when final versions are available on the website.

All modules of the RA guidelines are published and made freely available to all users on the main guidelines page of the RA website [9]. Each guideline has been formated as a pdf file at the foot of each module on the main guidelines page of the RA website to provide printable copies of each module ready for download from the website at no cost to all users.

The draft and planned guideline modules are published on the RA website in the future guidelines page [12].

The guidance is disseminated electronically to a wider target audience via the websites of NHS Evidence and Kidney Diseases Improving Global Outcomes (KDIGO):

(a) The RA guidelines are cited in the appropriate topic section within NHS Evidence - kidney diseases and male urogenital disorders which assists making the guidance more widely available (formerly a Specialist Library of the National Library for Health) [13].

(b) Comparison of the RA guidelines with other international nephrology guidelines is available on the Kidney Diseases Improving Global Outcomes (KDIGO) website [14].

\section{Implementation of the guidelines}

Implementation of the RA guidelines is promoted by the identification of audit measures related to key recommendations within the guidance. The audit measures may be used for local and regional audit by individual renal units and all of the renal units within a region. Implementation of the guidelines has been assisted greatly by the use of several of the audit measures for national comparative audit by the UK Renal Registry and the publication of the audit data in the annual reports of the UK Renal Registry.

Several of the audit measures from the guidelines have been adopted as 'indicators for quality improvement' by the National Institute for Health and Clinical Excellence (NICE) on behalf of the Department of Health [15].

There are inevitable difficulties in deriving and implementing 'best practice guidelines' from randomised controlled trial or other evidence. In routine clinical practice it is seldom possible to reproduce the conditions that generated the trial results, even if the trial report gives sufficient detail on how the treatment was implemented - which is seldom the case [16]. Trials seldom include patients with additional comorbidities to the condition under study [17], and co-morbidity can significantly alter the balance of risk and benefit of a given intervention. Clinical practice guidelines usually make statements about what treatments patients should receive, and make the tacit assumption that these choices are taken by the healthcare team, to which the guidelines are primarily addressed. In clinical practice, the patient may choose not to have a particular treatment. There is thus a potential conflict between patient autonomy and the reliable implementation of an intervention, so shared decision-making might be thought to reduce the proportion of patients whose treatment is 'within guidelines'; however, patients who feel that they have shared a decision about whether to take a given treatment, rather than being told to do so, are more likely to adhere to the treatment [18]. The Clinical Affairs Board of the RA acknowledges these concerns, but strongly believes that clinical practice guidelines in the complex field of kidney disease will do much more good than harm. Future editions of the guidelines may include decision-making tools to support individualised decision-making, concentrating first on areas where 
the risk:benefit ratio of a recommended intervention or treatment strategy may depend markedly on comorbidity or a patient's attitude to risk.

\section{Editorial Independence and Conflicts of Interest}

All co-authors are required to declare their potential conflicts of interest in the acknowledgements at the end of each module but having a potentially relevant conflict does not disqualify a potential author from contributing. None of the co-authors have or will acquire any financial gain from developing the recommendations in their guideline module.

\section{Executive summary of the fifth edition of the Renal Association guidelines}

The current edition of the RA guidelines is a combination of updates of the 6 guideline modules of the fourth edition (2007-2009) and the addition of 8 new guideline modules to provide guidance in all of the main areas of chronic kidney disease (CKD), renal replacement therapy (RRT) and acute kidney injury (Table 1).

The RA Clinical Practice Guidelines are not funded by any external organisation, commercial company or charity. The Clinical Practice Guideline Committee receives no funding apart from minor expenses from the RA Executive to cover the cost of an annual meeting, which is held during the Annual Meeting of the RA,

Table 1. Index of the 5th Edition of the Renal Association Clinical Practice Guidelines

\begin{tabular}{|c|c|c|}
\hline Renal Association Clinical Practice Guideline & Date of final version & Planned year of update \\
\hline $\begin{array}{l}\text { Prevention of Blood Borne Virus Infection in Chronic Kidney Disease - } \\
\text { Dr Colin Geddes, Dr Elizabeth Lindley and Dr Neill Duncan }\end{array}$ & $14 / 07 / 09$ & 2012 \\
\hline $\begin{array}{l}\text { Planning, Initiation and Withdrawal of Renal Replacement Therapy - } \\
\text { Prof Ken Farrington and Dr Graham Warwick }\end{array}$ & $17 / 09 / 09$ & 2012 \\
\hline $\begin{array}{l}\text { Peritoneal Dialysis Access - } \\
\text { Dr Martin Wilkie, Dr Sarah Jenkins and Mr Badri Shrestha }\end{array}$ & $22 / 09 / 09$ & 2012 \\
\hline $\begin{array}{l}\text { Haemodialysis - } \\
\text { Dr Robert Mactier, Dr Nic Hoenich and Dr Cormac Breen }\end{array}$ & $01 / 12 / 09$ & 2012 \\
\hline $\begin{array}{l}\text { Nutrition in Chronic Kidney Disease - } \\
\text { Dr Mark Wright and Dr Colin Jones }\end{array}$ & $25 / 06 / 10$ & 2013 \\
\hline $\begin{array}{l}\text { Peritoneal Dialysis - } \\
\text { Dr Graham Woodrow and Prof Simon Davies }\end{array}$ & $30 / 07 / 10$ & 2013 \\
\hline $\begin{array}{l}\text { Cardiovascular Disease in Chronic Kidney Disease - } \\
\text { Dr Stephen Holt and Dr David Goldsmith }\end{array}$ & 06/08/10 & 2013 \\
\hline $\begin{array}{l}\text { Anaemia in Chronic Kidney Disease - } \\
\text { Dr Ashraf Mikhail, Dr Rajesh Shrivastava and Dr Donald Richardson }\end{array}$ & $15 / 11 / 10$ & 2013 \\
\hline $\begin{array}{l}\text { Mineral and Bone Disorders in Chronic Kidney Disease - } \\
\text { Dr Simon Steddon and Dr Edward Sharples }\end{array}$ & $06 / 12 / 10$ & 2013 \\
\hline $\begin{array}{l}\text { Vascular Access For Haemodialysis - } \\
\text { Dr Richard Fluck and Dr Mick Kumwenda }\end{array}$ & $05 / 01 / 11$ & 2014 \\
\hline $\begin{array}{l}\text { Assessment of the Potential Kidney Transplant Recipient - } \\
\text { Dr Chris Dudley and Dr Paul Harden }\end{array}$ & $12 / 01 / 11$ & 2014 \\
\hline $\begin{array}{l}\text { Post-operative Care of the Kidney Transplant Recipient - } \\
\text { Dr Richard Baker, Professor Alan Jardine and Dr Peter Andrews }\end{array}$ & $05 / 02 / 11$ & 2014 \\
\hline $\begin{array}{l}\text { Detection, Monitoring and Management of Patients with Chronic Kidney } \\
\text { Disease - } \\
\text { Dr Mark MacGregor and Dr Maarten Taal }\end{array}$ & $28 / 02 / 11$ & 2014 \\
\hline $\begin{array}{l}\text { Acute Kidney Injury - } \\
\text { Dr Andrew Lewington and Dr Suren Kanagasundaram }\end{array}$ & $08 / 03 / 11$ & 2014 \\
\hline
\end{tabular}


Table 2. Summary of the 5th Edition of the Renal Association Clinical Practice Guidelines

\begin{tabular}{|c|c|c|c|}
\hline Renal Association Clinical Practice Guideline & $\begin{array}{l}\text { Number of } \\
\text { topic headings }\end{array}$ & $\begin{array}{l}\text { Number of } \\
\text { recommendations }\end{array}$ & $\begin{array}{l}\text { Number of } \\
\text { audit measures }\end{array}$ \\
\hline Prevention of Blood Borne Virus Infection in Chronic Kidney Disease & 7 & 36 & 6 \\
\hline Planning, Initiation and Withdrawal of Renal Replacement Therapy & 6 & 25 & 20 \\
\hline Peritoneal Dialysis Access & 7 & 14 & 2 \\
\hline Haemodialysis & 9 & 51 & 15 \\
\hline Nutrition in Chronic Kidney Disease & 4 & 16 & 9 \\
\hline Anaemia in Chronic Kidney Disease & 6 & 28 & 12 \\
\hline Peritoneal Dialysis & 7 & 25 & 23 \\
\hline Cardiovascular Disease in Chronic Kidney Disease & 5 & 27 & 10 \\
\hline Mineral Bone Disorders in Chronic Kidney Disease & 4 & 7 & 4 \\
\hline Vascular Access for Haemodialysis & 6 & 19 & 4 \\
\hline Assessment of the Potential Kidney Transplant Recipient & 2 & 18 & 11 \\
\hline Post-operative Care of the Kidney Transplant Recipient & 11 & 71 & 46 \\
\hline $\begin{array}{l}\text { Detection, Monitoring and Management of Patients with Chronic Kidney } \\
\text { Disease }\end{array}$ & 2 & 25 & 42 \\
\hline Acute Kidney Injury & 12 & 49 & 24 \\
\hline Total & 88 & 411 & 228 \\
\hline
\end{tabular}

and the secretarial costs for typesetting the draft and final versions of the guideline modules.

Within the 14 guideline modules there are a total of 411 peer reviewed guideline recommendations and 228 audit measures under 88 search topic headings (Table 2).

Each of the RA guideline modules of the fifth edition listed in Table 2 is published in full as separate documents in this issue of Nephron Clinical Practice apart from the guideline on peritoneal dialysis access, which has been adopted by the International Society of Peritoneal Dialysis (ISPD) and published previously in Peritoneal Dialysis International [19].
An user friendly summary of all of the guideline recommendations in the 14 guideline modules is published separately in this supplement before the full guidelines to provide a desk reference of the fifth edition of the RA guidance.

In addition the Renal Association Clinical Practice Committee has collaborated with other specialities to produce interspecialty, peer reviewed guidelines which are available on the 'Other Guidelines' page of the Renal Association website [20]. 


\section{References}

1 The National Service Framework for Renal Services Part One: Dialysis and Transplantation. Department of Health, January 2004

2 The National Service Framework for Renal Services Part Two: Chronic kidney disease, acute renal failure and end of life care. Department of Health, February 2005

3 Designed to Tackle Renal Disease in Wales http://wales.gov.uk/topics/ health/publications/health/strategies/designedrenal?lang=en

4 Clinical Standards. Adult Renal Services, NHS Scotland, February 2002 http://www.nhshealthquality.org/nhsqis/files/Renal_AdultRenalServices_ 04.pdf

5 http://www.renal.org/Clinical/OldGuidelines.aspx

6 Atkins D, Best D, Briss PA, et al. GRADE Working Group. Grading quality of evidence and strength of recommendations. BMJ 2004;328: 1490.

7 Uhlig K, MacLeod A, Craig J, et al. Grading evidence and recommendations for clinical practice guidelines in nephrology. A position statement from Kidney Disease: Improving Global Outcomes (KDIGO). Kidney Int 2006;70:2058-2065

8 Uhlig K, Balk EM, Lau J, Levey AS. Clinical practice guidelines in nephrology - for worse or for better. Nephrol Dial transplant 2006; 21:1145-1153

\section{Acknowledgements}

The peer review process is dependent on rapid editing on the RA website: e-publication of the first and final drafts and final versions of the fifth edition has been
$9 \mathrm{http}: / /$ www.renal.org/Clinical/GuidelinesSection/Guidelines.aspx

$10 \mathrm{http} / / / \mathrm{www}$. evidence.nhs.uk/Accreditation/Pages/AccreditationDecisions. aspx

$11 \mathrm{http} / / /$ www.renal.org/Clinical/RenalRegistry.aspx

$12 \mathrm{http}: / /$ www.renal.org/Clinical/GuidelinesSection/FutureGuidelines.aspx

$13 \mathrm{http} / /$ www.library.nhs.uk/kidney/SearchResults.aspx?catID=15055

14 www.kdigo.com

15 http://www.nice.org.uk/aboutnice/qualitystandards/indevelopment/ chronickidneydisease.jsp

16 Glasziou P, Chalmers I, Altman DG, et al. Taking healthcare interventions from trial to practice. Br Med J 2010;341:c3852

17 Tinetti ME, Bogardus ST Jr, Agostini JV. Potential pitfalls of diseasespecific guidelines for patients with multiple conditions. N Engl J Med 2004;351:p. 2870-2874

18 Elwyn G, Laitner S, Coulter A, Walker E, Watson P, Thomson R. Implementing shared decision making in the NHS. Br Med J 2010;341:c5146

19 Figueiredo A, Goh B, Jenkins S, Johnson DW, Mactier R, Ramalakshmi S, Shrestha B, Struijk D, Wilkie M. Clinical Practice Guidelines for Peritoneal Access. Perit Dial Int 2010;30:424-429

$20 \mathrm{http} / /$ www.renal.org/Clinical/GuidelinesSection/OtherGuidelines.aspx

facilitated greatly by the expertise of Damien Clarke, MCI, Petersfield/London. 